\title{
Pituitary Stalk Thickening Post-
}

\section{Commencement of Dialysis: Case Report}

\section{Department of Diabetes and Endocrinology, West Hertfordshire Hospitals NHS Trust}

\section{Background}

Non-neoplastic pituitary stalk thickening is rare in patients without infiltrative disorders or diabetes insipidus.

Although hyperprolactinaemia is a recognised abnormal endocrine finding in patients with end stage renal failure (ESRF), it is unusual for serum prolactin levels to be $>1000 \mathrm{mu} / \mathrm{l}$.

We present a non-diabetic patient with end stage renal failure with hyperprolactinaemia associated with pituitary stalk thickening.

\section{Case Patient}

A 53 year old Nigerian gentleman with a background of established end stage renal failure caused by refractory hypertension and receiving haemodialysis, presented with reduced libido, erectile dysfunction $\&$ painful gynaecomastia in 2010 . He had no galactorrhoea, headaches or visual disturbances.

\section{Progress}

His serum prolactin was found to be elevated at $2683 \mathrm{mu} / 1$ with evidence of secondary hypogonadism (serum testosterone $6.3 \mathrm{nmol} /, \mathrm{FSH} 9.2 \mathrm{U} / \mathrm{L}, \mathrm{LH}$ $0.9 \mathrm{U} / \mathrm{L}$, seum oestradiol $48 \mathrm{pmol} / \mathrm{l})$. Serum ESR was $14 \mathrm{mmol} / \mathrm{hr}$, serum electrophoresis, LFT's and ACE 37 U/L, i.e. normal. Corrected calcium was 2.34 $\mathrm{mmol} / \mathrm{l}$, urine electrophoresis and Chest Radiograph were normal. MRI pituitary (2011) showed an expansion in the pituitary stalk measuring $5 \mathrm{~mm}$ with minimal mixed signal. Radiologists suggested this finding's differentials for this appearance could be granulomatous disease, amyloid or neoplastic change within. The patient was discussed with neurosurgeons at the joint pituitary clinic; it was recommended not to biopsy the lesion \& treat his prolactin medically.

\section{Imaging}

MRI Pituitary 2011 - stalk thickening
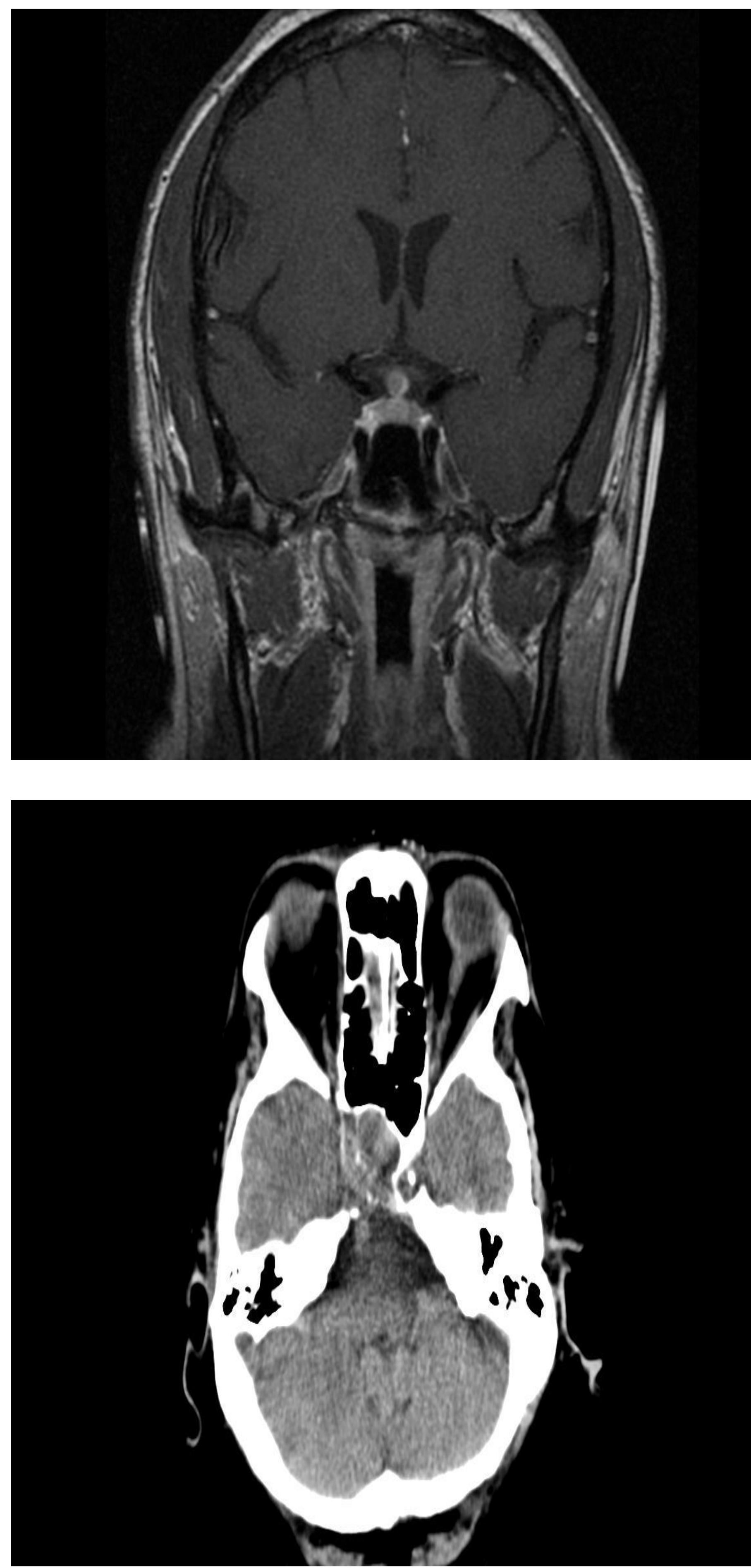

He was commenced on Bromocriptine which normalised his prolactin.

He improved symptomatically, but gynaecomastia persisted.

In 2012, the patient stopped Bromocriptine due to nausea. He was switched to Cabergoline and testim gel were commenced. A repeat MRI in 2012 showed no interval change despite the commencement of dopamine agonist therapy.
Recent literature notes that patients in dialysis-dependent kidney failure are at significant risk for a recently described scleroderma-like disorder called nephrogenic systemic fibrosis. ${ }^{2}$

Nephrogenic systemic fibrosis (NSF) is associated with dermopathy and multiorgan dysfunction. No prior reports note pituitary involvement. Gadolinium-based contrast agents have been implicated in the development of nephrogenic systemic fibrosis. ${ }^{3}$

Our patient had a normal prolactin prior to receiving gadolinium for his $\mathrm{MR}$ Renal Angiogram prior to commencing dialysis. We hypothesise his pituitary stalk thickening, which did not change post-bromocriptine is secondary to NSF.

\section{Discussion}

- The Royal College of Radiology Guidelines ${ }^{4}$ state that:

- NSF may develop from the day of exposure for upto 3 months.

-Patient risk factors - renal impairment (GFR $<60$, dialysis patients included), patients awaiting/post-liver transplant and patients under the age of one.

-Contrast risk factors - NSF has occurred post Omniscan, Magnevist and Optimark.

-Preventing NSF - use the lowest dose of contrast agent possible, avoid the above-mentioned agents and try not to re-scan within one week.

\section{References}

1. Byrne, T. N. Etiology of Thickened Pituitary Stalks MGH Neuroendocrine Clinical Center Bulletin. Spring 2008, Volume 14 No 1

Delman, B. Imaging of Paediatric Pituitary Abnormalities. Endocrinol Metab Clin N Am 38 (2009) 673-698

3. Fretellier et al - Nephrogenic Systemic Fibrosis-Like Effects of Magnetic Resonance Imaging Contrast Agents in Rats with Adenine-Induced Renal Failure. Toxicol. Sci. (September 2012)

4. Royal College of Radiologists Guidance on NSF, 2007. 